\title{
Rachel Jackson: 'There is no more poignant time to consider art as therapy'
}

\author{
By Kate Quinlan
}

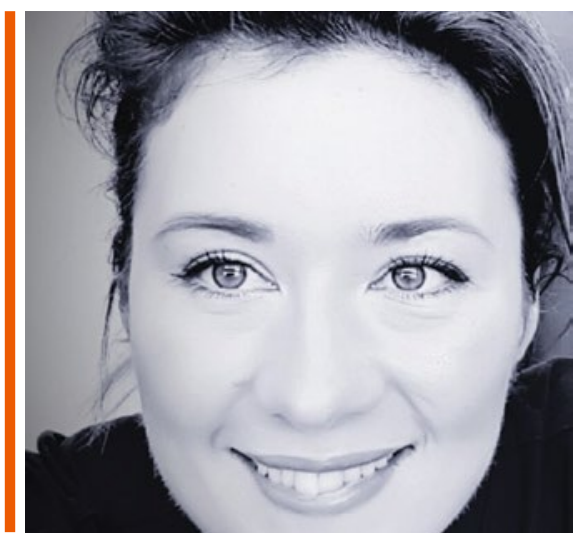

Are there dentists or artists in your family?

There are no dentists. My family can't understand why I chose this path to be honest. My mother is a retired self-taught artist; she has a beautiful imagination and draws this out of me as my approach is a little more disciplined.

\section{What attracted you to medical illustration, as opposed to studying fine art or another art subject?}

The human body and my general scientific intrigue - where art was more a formal method to communicate than that set out by contemporary, abstract or even fine art. Medical illustration felt purposeful and I felt comfortable in my abilities in this area too.

\section{How much of your medical illustration degree focused on dentistry/teeth?}

Very little from an arts and illustration point of view. We attended lectures on general systems of the body, anatomy lab and physiology etc, alongside the medics and nurses. The only dental aspect was within my remit as a clinical photographer, taking standard orthodontic views. My knowledge of dentistry and in dental health was very little.

\author{
Rachel Jackson started her career as a medical illustrator in Glasgow, moved \\ to the Highlands to start a family, trained as a dental therapist, became a \\ tutor on the Oral Health Science course she had completed... then in 2017, \\ she began studying for her BDS in Aberdeen. Rachel is also an artist and has \\ recently launched a Facebook Group called the Creative Dental Network.
}

After graduating, you worked as a medical illustrator for hospitals in Glasgow. What did this entail exactly?

I worked within a small team of graphic designers, artists, illustrators and photographers based within a very busy hospital. My role was to aid the communication of the medical and dental profession, between each other and to the public. This was most often in the form of photographic documentation of surgical procedures and disease monitoring. On occasions I was expected to document the effects of serious crimes, which was a steep learning curve.

From a creative aspect I would work with consultants and surgeons to illustrate medical textbooks and surgical concepts. This close working dynamic provided me with an unbounded form of medical education, one that crossed many healthcare disciplines. I began to fall in love with healthcare.

\section{Why did you decide to go back to} university to study dental therapy?

I had moved back to the Highlands, where I am from, now with a young child. The job prospects were limited. I decided to move into the dental field as I saw this as another clinical environment, one with direct patient contact and another opportunity to learn. I began working as a dental nurse within a department where a new dental therapy school was to be built. I watched with intrigue, and loved the idea of moving to the other side of the dental chair. I was supported by my colleagues to progress too. I could see a spark of creativity in the dentists I had assisted and knew my artistic abilities and clinical and patient experiences thus far could be applied but in a new role.

\section{Was it difficult to gain a place on the Oral Health Science course?}

No, it wasn't. My qualifications, experience, maturity and good standing helped with the application. I had worked with vulnerable groups and had actioned dental public health initiatives within remote and rural communities. I discussed art in dentistry for the first time during my interview actually, simply as evidence to support skills such as precision and dexterity. The feedback was encouraging, and I was excited.

\section{How did you find balancing your studies with family life?}

I began when my daughter started school which eased the pressure a little. I have a very supportive family and tend to work with a certain level of stress anyway. It is pressure that keeps me going, moving forward it seems. I actually work better that way. It had its 


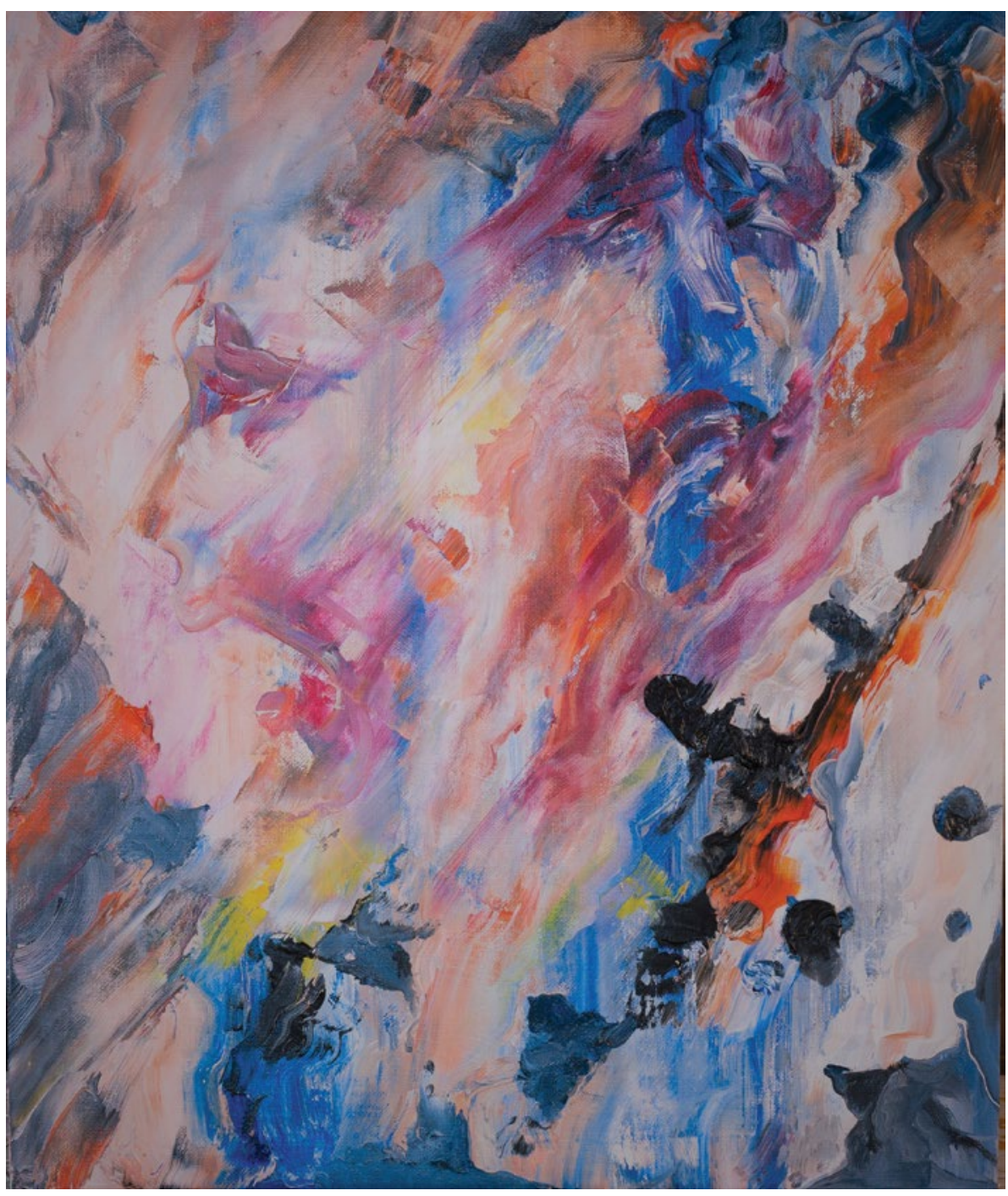

Sadness and Sorrow (oil on canvas)

moments; I was building a house too. I can't say that I will ever do that again!

\section{Did you move straight into general practice after graduating?}

Acquiring a job as a dental therapist was straightforward. I would say I was lucky, but it wasn't luck, it was hard work and the fortune in meeting open minded practitioners. Mixed with a growing reputation, dedication and teamwork, that ensured I was working within the salaried service, general and private practice, to my full remit from the off.

\section{Did you enjoy being a dental therapist and going back to teach on your degree course?}

I enjoyed my job very much; it was the people I worked with that made every day an enjoyable one. I had a very supportive dental manager too. Yet I have an odd nature that causes me to immerse myself in one project after another.
I need to be challenged; I sometimes think what on earth am I searching for? But it is that constant drive to learn and create that carries me along. It was within a year of graduating that I began to get itchy feet and tried many things to overcome it.

I was working for several dentists each week. Through observing their work, patients, planning and its execution I grew out of my role very quickly. This was a significant form of peer review. I realised that the dentists had no one to compare their work with as I did. The power of peer review is so significant in understanding one another, which means that care has the same value for all with respect to carrying on a common pursuit. Healthcare first! I believe that peer review should be a compulsory part of continuing professional development across all sectors of dentistry.

Feeling I had more to give and more to learn I moved into teaching. I had a great deal to learn but looking back I think that teaching was in fact the most creative and artistic part of my career to date. You do not have to be a fountain of knowledge to teach but you do have to be able to bring something into the world that did not exist before. The ethos of dental education should be the creation of human subjectivity: to create a person that is able to reflect and take action on his or her own questioning, as well as the dental theory.

\section{What led you to applying for dentistry?}

Back then it was the frustration within the confines of my remit; my love for restorative dentistry and my desire for the next challenge. I thought I knew what a dentist was, what I was entering into. I thought that the transition from therapist to dentist was straightforward. But I was wrong. Anyone that says it is a small step up the career ladder is wrong; it is an entirely different role and identity. The skill set of a dental therapist is a solid one for sure and brings with it an inherent caring nature, a very holistic mindset, which is a vital start to dentistry. Yet this is overshadowed by the theory of medicine, anatomy and physiology, which results in an even playing field within a postgraduate entry course to be honest.

\section{Was it daunting to embark on your third period of higher education - and the longest yet?}

Yes, I remember getting teary with my boss, questioning what I had done. That was it ... I was giving up security, a job that others would beg for, time with my family, finances, a 'normal' family routine. I knew my role, my identity and position within the workforce. I could execute it well and was surrounded by supportive colleagues. Yet every day I searched for more.

I was at the BDA wellbeing meeting a few weeks ago and the word 'valued' was concluded to be a prominent intrinsic form of motivation that in turn improves mental health. It is feeling valued within a team, within a plan, within a person's care, that results in motivation for more, motivation to do well. Dentistry could provide me with more; teaching will provide me with even more. Therefore, a person is more willing to adapt and sacrifice as you face the next hurdle.

\section{How have you found your studies at dental school so far?}

I had organised my life to ensure the pressures of leaving paid employment and becoming a student again were manageable. 


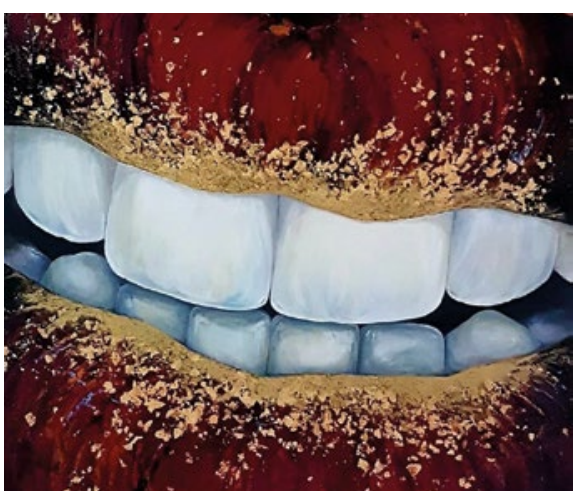

In Fashion

14 It has been an amazing rollercoaster so far, with more ups than downs. I am provided with an amazing education, facilities and nurtured by experienced knowledgeable staff and as a group of students we take care of each other too. I would be lying if I said it was easy, the volume of work in a condensed course is unbelievable.

\section{When will you graduate?}

2021 ... in style one hopes! I plan on having an exhibition to conclude my journey as a dental student. My studies have led to the production of artwork: this is my visual diary, one of a dental student. This is a window into the profession, the dedication, the skill and knowledge of each and every one of us. It is the side of us that is not well represented in society and needs to be shown to the public, to our patients.

\section{Have you been able to continue as an artist throughout your studies and career to date?}

I hadn't thought of it as a continuous journey as I hadn't lifted a paintbrush since I left medical illustration in 2007. I identified myself as an artist in year two of the BDS programme, through the inspiration of my dental education. When I finally did lift a paintbrush, I had even shocked myself. My skills as an artist had grown through the continuous tuning of precision, an appreciation for shape and form that came from dentistry, as the only thing I had in my hands for all those years was a drill.

The artwork was to bridge my world at university and that of my daughter; I chose to illustrate what I was learning. To allow her into my world, to see what mum was doing, to educate her and have little projects to do together too. I found it was useful from my educational perspective too. I could concisely convey large volumes of theory and concepts into one image. I would close my eyes and

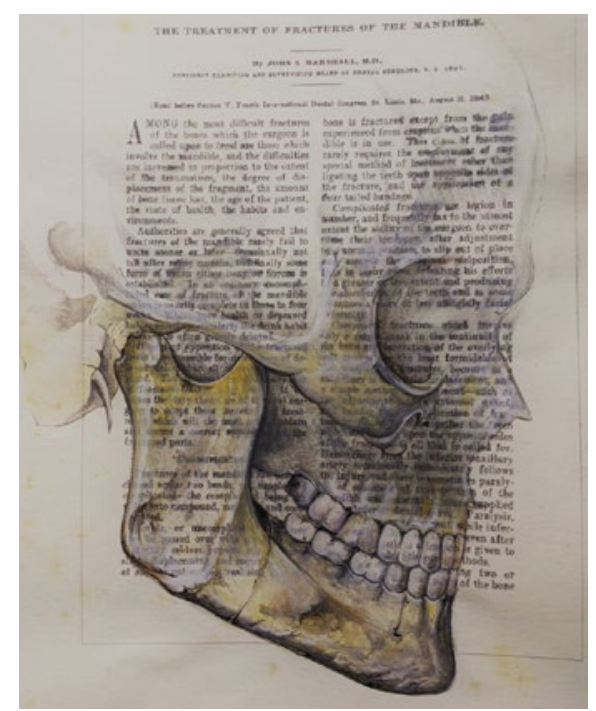

Fractured Mandible 1904

remember the theory on the page. This was just as I did as a medical illustrator, removing the 'noise' from a surgical procedure to illustrate a technique.

This was the first time I realised that the art of dentistry could be in the form of education.

I have a studio back home in Inverness; outside of that it is the windowsill in my shared student flat, driving my flatmate bonkers with my latest pedantic pursuit.

\section{Do you think artistic ability is an important skill for the dentist?}

Without a doubt. When I started dental school, I felt I was the wrong shape for dentistry. I was not heavily science minded. I was going to leave in fact. For a moment I thought that the artistic ability I have, had only a very small place, one solely associated with aesthetic and restorative dentistry. I use a drill as well as I use a paintbrush, but after my institute gave me the freedom to find myself within the profession, I have discovered a much greater appreciation for artistic abilities within dentistry. It's a very exciting time. I smile as I answer this question as it is so exciting to have come to so many eureka moments in getting here. My institute embrace it; they listen, they support and they have created an environment that I can grow within and I have met so many inspirational people. So far yes, dexterity, shape, form, colour, texture, negative shapes and precision go hand in hand with clinical skill. We might all agree on that. However, there is a deeper artistic skill yet to be recognised within dentistry and that is in connecting with our patients, as an educational tool, wellbeing and areas such as reflective practice and the professionalism domains.

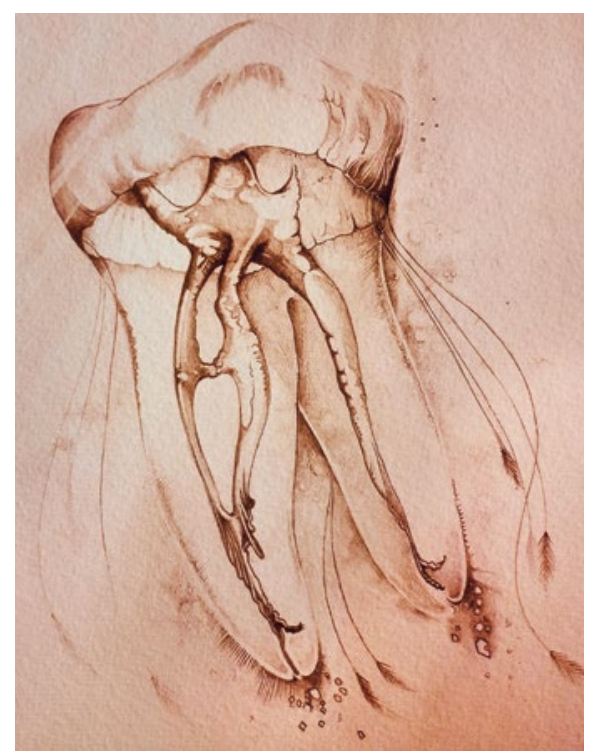

Jelly Molar

\section{Do you find producing art therapeutic?}

Yes, it is an escape from the boundaries of the profession. I can take risks without worry, make mistakes without fear. It is an artist's freedom that has allowed me to develop a reflective open mind, one that is not fearful of failure, and this helps my clinical development. There is no more poignant time to consider art as therapy than now, and after the effects of COVID-19. I am not about to insult everyone by saying this is a remedy to a devastating situation for many, but it is an outlet just as exercise is or any hobby for that matter. In creating a healthy, stronger mind in times of trouble.

All of my work is inspired by dentistry and dentistry alone. The inspiration behind each piece might surprise people but it happens, which is how I might better convey to the profession just how an artist can fit within dentistry and how those skills are of use. I have a mental list of paintings that I just need to find time to complete. One is a burden to me a little at the moment. It's a large oil painting that sees the perception of an anaesthetised patient on the anaesthetist and on the surgeon himself. It looks to propose that the anaesthetist always perceives the living but that the surgeon perceives the dead to negate himself from humanity to fulfil his role in that moment. It is a work in progress and will take a few years.

\section{How could art influence teaching at undergraduate level for a future curriculum?}

This is an area that I look to research. I am looking to 'bridge the gap' between nonclinical and clinical practice with art-based 


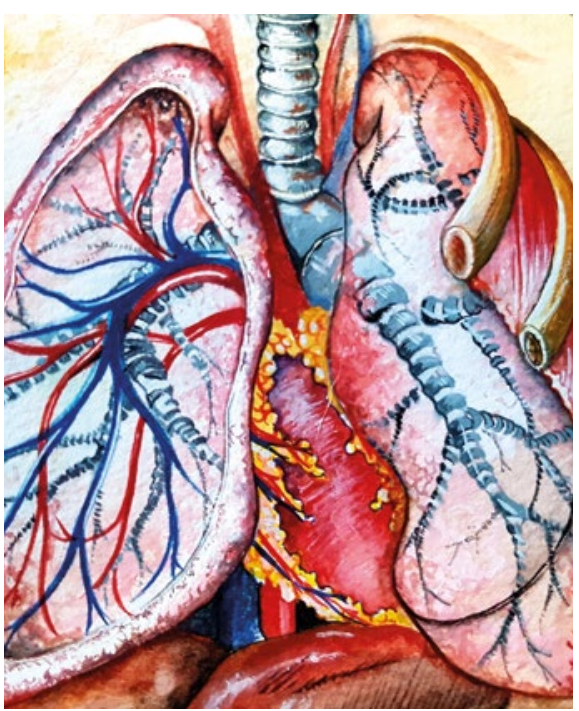

Lungs

teaching methods. To design a humanities thread fit for dentistry. I say thread as it needs to be woven throughout all years but it must connect the art and science of our profession.

The arts can tap into so many curriculum domains. Restorative dentistry for sure, that's the easy one. For me it is the scientifically disciplined artist that can facilitate art in dentistry as it speaks our language. There is no point me coming at the profession with some abstract concept: the crazy artist angle. Art in dentistry has to incorporate science and practical skills first. That will set the foundation for more complex, deeper thinking and practical skill moving forward. For example, education happens through communication, not spoken or written words alone. In facilitating creativity, we are able to know more about the sick person and the illness than just the name of the disease and the science that explains it.

Times have changed, dentistry is still very traditional in many ways, yet society and the dental student has changed a great deal. Therefore, education has to adapt if we are to create a dentist fit for this profession and its future. When education is broader and freer there will be more opportunity for each to find their place.

\section{What are your plans for the coming few years?}

Like all dental students right now we are adapting within unusual times due to the viral pandemic which causes a level of uncertainty.

I never wish my time away though - yes it's hard - but at the same it is not a hardship to be in an environment overflowing with the treasures of education. To be nurtured, to help

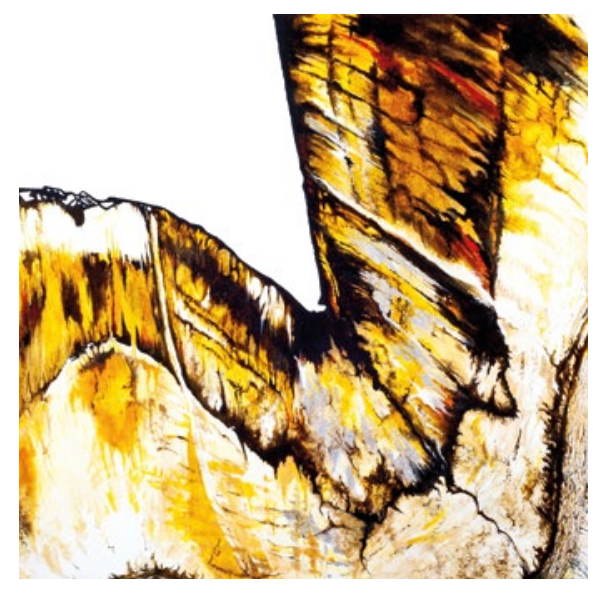

Carious Fissure

others, to be valued and to grow. Each of us must remember what a privilege it is to enter into this profession.

I will begin my research project and facilitate art workshops within my institute in the next academic year, I hope. Students and I have introduced Creative Dental Network on Facebook so as to facilitate creative opportunities for staff and students that in turn focus on wellbeing. I look to encourage dental students from across the UK to embark on a wellbeing within dentistry campaign, in which they contribute with their own artwork to a mental health awareness charity calendar. If anyone could help support this I would love to hear from them.

I will continue to produce artwork and have several commissions on the go. Anything from personal artwork that reflects a dentist's career path and their identity within the profession, to illustrating modern implant techniques for educational purposes. I am using Italian Renaissance art to allow implantology to be viewed and conveyed in a new and very beautiful way (see image, Implant Surgery \#1).

I will continue to add to the 'live in gallery' at The Campbell Academy in Nottingham and have another exhibition planned: Edinburgh with the BACD in November 2020. The title of this is 'Seeing is Believing'; currently if you can imagine dental structures, anything from enamel under a microscope to $\mathrm{x}$-rays, implants and biology mixed with a kaleidoscope, geometry and lights. That's the inspiration for the artwork. This will be coupled with my own exploration of what beauty means to dentistry and society today.

\section{Do you have a career plan for when you graduate?}

I intend to move into teaching part time and practising part time. The inspiration for

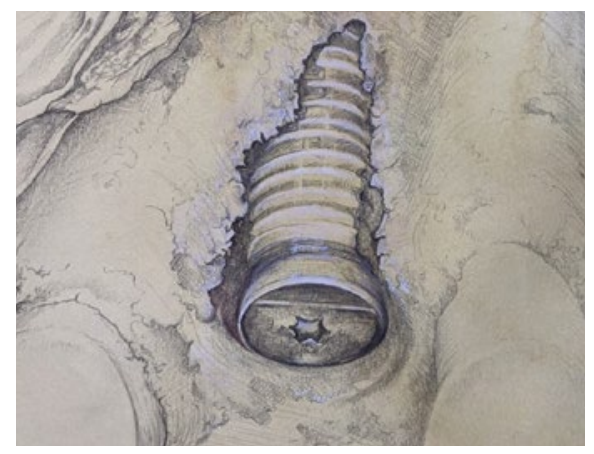

Implant Surgery \#1

the artwork will come and I will continue producing work.

I have begun developing my own postgraduate workshops for the dental profession and look to have that as a standalone or combine with other education providers. I will continue my postgrad teaching qualification and would love to complete an MSc in restorative dentistry. I have met so many influential people from across the world and hope to continue to do so.

\section{Is there anything else you would like to share with readers of the $B D J$ ?}

I would like to ask anyone that might be interested in developing a charitable project focusing on the wellbeing of the dental profession and for any students that would like to contribute to an exhibition to get in touch.

I would like to give you an example of how the artist's mindset can facilitate education, both from a learner and an observer's perspective. This example is particularly meaningful in the current climate I think. It is the inspiration behind the painting 'Sadness and Sorrow' (pictured).

'Sadness and Sorrow' is an oil painting inspired by an extraordinary conversation I had with an oral medicine specialist. We had been discussing the psychology of pain management before he asked, 'Rachel could you paint pain?' I thought 'what type? It's so subjective!'

I spent a few months exposed to the emotions of patients and their families within the local hospital and hospice and produced abstract art seen in 'Sadness and Sorrow' where colour is used to create the noise of sadness and the texture of pain. The process saw me enter the 'human dimension' of the dental professional and its relationship with patients.

Rachel is happy to be contacted at rjmedink@ gmail.com.Instagram @rjmedink.

www.medink.co.uk. 